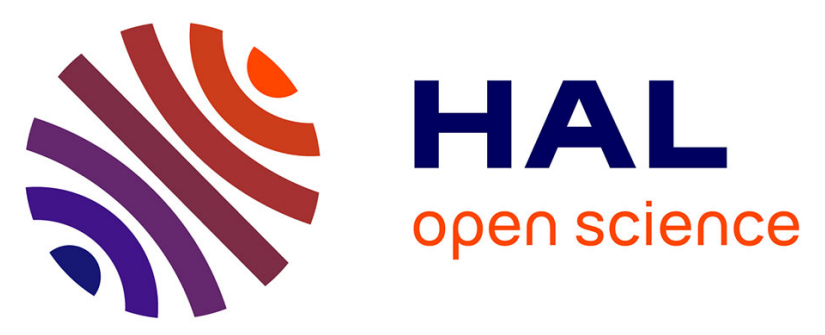

\title{
Concurrent observations of the ultraviolet nitric oxide and infrared O2 nightglow emissions with Venus Express
}

\author{
J.-C. Gérard, Christopher M. Cox, L. Soret, A. Saglam, G. Piccioni, \\ Jean-Loup Bertaux, P. Drossart
}

\section{- To cite this version:}

J.-C. Gérard, Christopher M. Cox, L. Soret, A. Saglam, G. Piccioni, et al.. Concurrent observations of the ultraviolet nitric oxide and infrared O2 nightglow emissions with Venus Express. Journal of Geophysical Research. Planets, 2009, 114 (E9), pp.E00B44. 10.1029/2009JE003371 . hal-00399592

\section{HAL Id: hal-00399592 \\ https://hal.science/hal-00399592}

Submitted on 11 Mar 2016

HAL is a multi-disciplinary open access archive for the deposit and dissemination of scientific research documents, whether they are published or not. The documents may come from teaching and research institutions in France or abroad, or from public or private research centers.
L'archive ouverte pluridisciplinaire HAL, est destinée au dépôt et à la diffusion de documents scientifiques de niveau recherche, publiés ou non, émanant des établissements d'enseignement et de recherche français ou étrangers, des laboratoires publics ou privés. 


\title{
Concurrent observations of the ultraviolet nitric oxide and infrared $\mathrm{O}_{2}$ nightglow emissions with Venus Express
}

\author{
J.-C. Gérard, ${ }^{1}$ C. Cox, ${ }^{1}$ L. Soret, ${ }^{1}$ A. Saglam, ${ }^{1}$ G. Piccioni, ${ }^{2}$ J.-L. Bertaux, ${ }^{3,4}$ \\ and P. Drossart ${ }^{5}$ \\ Received 19 February 2009; revised 4 May 2009; accepted 18 June 2009; published 22 September 2009.
}

[1] Two prominent features of the Venus nightside airglow are the nitric oxide $\delta$ and $\gamma$ bands produced by radiative association of $\mathrm{O}$ and $\mathrm{N}$ atoms in the lower thermosphere and the $\mathrm{O}_{2}$ infrared emission generated by three-body recombination of oxygen atoms in the upper mesosphere. The $\mathrm{O}_{2}$ airglow has been observed from the ground, during the Cassini flyby, and with VIRTIS on board Venus Express. It now appears that the global structure of the two emissions shows some similarities, but the statistical location of the region of strongest emission is not coincident. The Spectroscopy for Investigation of Characteristics of the Atmosphere of Venus (SPICAV) ultraviolet spectrograph has collected a large number of spectra of the Venus nitric oxide nightside airglow. Visible and Infrared Thermal Imaging Spectrometer (VIRTIS) images have been obtained at the limb and in the nadir-viewing mode and have provided new information on the horizontal and vertical distribution of the emission. We present the first concurrent observations of the two emissions observed with Venus Express. We show that nadir observations generally indicate a low degree of correlation between the two emissions observed quasi-simultaneously at a common location. A statistical study of limb profiles indicates that the altitude and the brightness of the two airglow layers generally do not covary. We suggest that this lack of correlation is explained by the presence of strong horizontal winds in the mesosphere-thermosphere transition region. They carry the downflowing atoms over large distances in such a way that regions of enhanced NO emission generally do not coincide with zones of bright $\mathrm{O}_{2}$ airglow.

Citation: Gérard, J.-C., C. Cox, L. Soret, A. Saglam, G. Piccioni, J.-L. Bertaux, and P. Drossart (2009), Concurrent observations of the ultraviolet nitric oxide and infrared $\mathrm{O}_{2}$ nightglow emissions with Venus Express, J. Geophys. Res., 114, E00B44, doi:10.1029/2009JE003371.

\section{Introduction}

[2] Planetary airglow is a powerful way to remotely probe the characteristics of atmospheres from an orbiting or flying-by spacecraft that complements in situ measurements. In particular, the study of airglow morphology, time variations and brightness may provide key observations concerning atmospheric composition, temperature structure, transport processes and their response to the solar photon and particle inputs. In the case of Venus, the Venera and Pioneer Venus missions have shed new light on some of these aspects more than 25 years ago. The presence of the delta and gamma bands of nitric oxide in the Venus nightglow was detected and identified by Feldman et

\footnotetext{
${ }^{1}$ Laboratoire de Physique Atmosphérique et Planétaire, Université de Liège, Liège, Belgium.

${ }^{2}$ INAF, IASF, Rome, Italy.

${ }^{3}$ LATMOS, Verrières-le-Buisson, France.

${ }^{4}$ Institut Pierre Simon Laplace, Université de Versailles Saint Quentin, Guyancourt, France.

${ }^{5}$ LESIA, Observatoire de Paris, Meudon, France.
}

Copyright 2009 by the American Geophysical Union. 0148-0227/09/2009JE003371 al. [1979] using the ultraviolet spectrograph on board the International Ultraviolet Explorer (IUE). It was also observed by Stewart and Barth [1979] with the ultraviolet spectrometer on board the Pioneer Venus Orbiter (PVOUVS). The emission is produced by radiative recombination through inverse predissociation of nitrogen $\mathrm{N}\left({ }^{4} \mathrm{~S}\right)$ and oxygen $\mathrm{O}\left({ }^{3} \mathrm{P}\right)$ atoms and dominates the middle ultraviolet nightglow spectrum. In this process, excited NO molecules radiate the ultraviolet $\delta$ and $\gamma$ bands between 180 and $310 \mathrm{~nm}$ :

$$
\mathrm{N}+\mathrm{O} \rightarrow \mathrm{NO}\left(\mathrm{C}^{2} \mathrm{\Pi}\right)
$$

giving rise to

$$
\begin{gathered}
\mathrm{NO}\left(\mathrm{C}^{2} \Pi\right) \rightarrow \mathrm{NO}\left(\mathrm{X}^{2} \Pi\right)+\delta \text {-bands } \\
\mathrm{NO}\left(\mathrm{A}^{2} \Sigma, \mathrm{v}^{\prime}=0\right) \rightarrow \mathrm{NO}\left(\mathrm{X}^{2} \Pi\right)+\gamma \text {-bands }
\end{gathered}
$$

Emission from the $\mathrm{C}^{2} \Pi(\mathrm{v}=0) \rightarrow \mathrm{A}^{2} \Sigma(\mathrm{v}=0)$ transition at $1.224 \mu \mathrm{m}$ was recently observed with the Visible and Infrared Thermal Imaging Spectrometer (VIRTIS) - $\mathrm{M}$ in the 
Venus nightglow [García Muñoz et al., 2009]. The N and O atoms are mainly produced by dissociation of $\mathrm{N}_{2}$ and $\mathrm{CO}_{2}$ on the dayside by extreme ultraviolet (EUV) photons and photoelectrons.

[3] Stewart et al. [1980] obtained images of the Venus nightside in the $\delta(0,1)$ band at $198 \mathrm{~nm}$ every $24 \mathrm{~h}$ with PVOUVS when Pioneer Venus was near apoapsis. They showed that the emission was highly variable in brightness and morphology over consecutive $24 \mathrm{~h}$ periods. The location of the brightest spots ranged from 2130 to $0300 \mathrm{LT}$ and $39^{\circ} \mathrm{S}$ to $60^{\circ} \mathrm{N}$ [Bougher et al., 1990]. This variability appeared to be caused by instabilities in the large-scale circulation, possibly as a result of wind shears near the terminator or time-varying wave drag from gravity waves. Stewart et al. [1980] built up a statistical global map of the UV nightglow showing that the emission is concentrated in a bright spot located near 0200 local solar time, south of the equator. Bougher et al. [1990] estimated the emission rate of this enhanced emission to be $\sim 1.9$ kilorayleighs $(\mathrm{kR})$ whereas the average hemispheric nightside intensity is $0.48 \mathrm{kR}$. These observations confirmed the general picture where production of $\mathrm{O}$ and $\mathrm{N}$ atoms by solar EUV on the dayside is followed by global circulation to the nightside, downward transport and radiative recombination. The shift of the statistical bright spot toward dawn was interpreted as a signature of a residual superrotation into the lower thermosphere. A determination of the altitude of the emission peak by Gérard et al. [1981] concluded that the emission peak is located close to $115 \mathrm{~km}$. Using a one dimensional model, they derived an eddy diffusion coefficient $\mathrm{K} \sim 8 \times 10^{12} \mathrm{n}^{-1 / 2} \mathrm{~cm}^{2} \mathrm{~s}^{-1}$, where $\mathrm{n}$ is the total number density. The general picture of production of $\mathrm{O}$ and $\mathrm{N}$ atoms followed by transport to the nightside by the subsolar to antisolar circulation, downward turbulent mixing and radiative recombination appeared quantitatively consistent with the PV-OUVS observations. This concept was numerically validated by three-dimensional simulations using the Venus Thermospheric General Circulation Model (VTGCM) [Bougher et al., 1990]. The statistical location of the bright spot was reasonably well predicted by the threedimensional model and implied zonal winds of about 50$75 \mathrm{~m} \mathrm{~s}^{-1}$ in the $115-150 \mathrm{~km}$ region. The observed shift toward dawn of the statistical location of the airglow maximum was reproduced by the VTGCM.

[4] Limb observations of the spectrum of nightglow emission in the $\delta$ and $\gamma$ bands of NO with the Spectroscopy for Investigation of Characteristics of the Atmosphere of Venus (SPICAV) ultraviolet spectrometer on board Venus Express [Titov et al., 2006; Svedhem et al., 2007] have been recently reported by Gérard et al. [2008a]. The mean altitude of the emission layer was found to be located at $113 \mathrm{~km}$, with variations between 95 and $132 \mathrm{~km}$. The mean limb brightness of the total NO emission at the limb was $32 \mathrm{kR}$, but it is highly variable with limb intensities as large as $440 \mathrm{kR}$ and values below $5 \mathrm{kR}$ at northern midlatitudes. It was found that the mean altitude of the emission peak statistically drops with increasing latitude between $6^{\circ}$ and $72^{\circ} \mathrm{N}$. From model fits to observed profiles, they determined that the downward flux of $\mathrm{N}$ atoms at $130 \mathrm{~km}$ typically varies between $1 \times 10^{8}$ to $4 \times 10^{9}$ atoms $\mathrm{cm}^{-2} \mathrm{~s}^{-1}$. The eddy diffusion coefficient $\mathrm{K}$ deduced from comparisons to the observed limb profiles was significantly less than that determined from the observations made with the Pioneer Venus UV spectrometer at low latitudes during periods of high solar activity.

[5] The oxygen airglow $(0-0)$ emission at $1.27 \mu \mathrm{m}$ is the most intense nonthermal component in the Venus atmosphere. It belongs to the $\mathrm{a}^{1} \Delta_{\mathrm{g}}-\mathrm{X}^{3} \Sigma_{\mathrm{g}}$ Atmospheric Infrared system and corresponds to an electric dipole forbidden transition with a radiative lifetime of about $70 \mathrm{~min}$ [Miller et al., 2001]. It was first discovered in ground-based observations of Venus by Connes et al. [1979] and subsequently imaged with ground-based telescopes [Alien et al., 1992; Crisp et al., 1996; Lellouch et al., 1997; Ohtsuki et al., 2008; Bailey et al., 2008]. It was measured from space during the Cassini flyby with a local maximum brightness of about 4 MR [Drossart et al., 1993]. The oxygen IR nightglow appeared patchy, highly variable with asymmetries, often exhibiting multiple local maxima, with variations on time scales as short as $1 \mathrm{~h}$. A much weaker $\mathrm{O}_{2}$ airglow was also detected in the Herzberg II visible wavelengths [Krasnopolsky, 1986; Bougher and Borucki, 1994]. The $1.27 \mu \mathrm{m}$ emission is produced by recombination of oxygen atoms created by photodissociation of $\mathrm{CO}_{2}$ and $\mathrm{CO}$ at thermospheric altitudes on the dayside. As previously explained, $\mathrm{O}$ atoms are transported to the nightside by the global thermospheric circulation. Three-body recombination of $\mathrm{O}$ atoms in the upper nightside mesosphere $(95-110 \mathrm{~km})$ leads to $\mathrm{O}_{2}$ formation in excited states, followed by airglow emissions as the molecules relax to the $\mathrm{X}^{3} \Sigma_{\mathrm{g}}$ ground state:

$$
\mathrm{O}+\mathrm{O}+\mathrm{M} \rightarrow \mathrm{O}_{2} *+\mathrm{M}
$$

followed by

$$
\mathrm{O}_{2} * \rightarrow \mathrm{O}_{2}+\mathrm{h} \nu
$$

where $\mathrm{O}_{2} *$ indicates one of the excited states of the $\mathrm{O}_{2}$ molecule and $\mathrm{M}$ is any neutral constituent. A fraction of the $\mathrm{O}_{2}$ molecules, estimated to be about $7 \%$, is formed directly in the $\mathrm{a}^{1} \Delta_{\mathrm{g}}$ metastable state. A substantial fraction of the upper excited states cascades into the ${ }^{1} \Delta$ state, so that the net efficiency of the production of this state in the threebody recombination may be close to $100 \%$ [Crisp et al., 1996]. Below the emission peak, $\mathrm{O}_{2}{ }^{1} \Delta_{\mathrm{g}}$ molecules may be deactivated by collisions with $\mathrm{CO}_{2}$, causing nonradiative transitions to the $\mathrm{O}_{2}$ ground state. The altitude of the peak of the $1.27 \mu \mathrm{m}$ emission is thus controlled by the competition between vertical transport, recombination and quenching of $\mathrm{O}$ atoms. The emission rate is related to the downward flux of oxygen atoms.

[6] The VIRTIS-M O $\mathrm{O}_{2}$ airglow limb observations have been presented by Drossart et al. [2007a], Gérard et al. [2008b, 2009], and Piccioni et al. [2009a]. Drossart et al. [2007a] determined that the $\mathrm{O}_{2}$ peak emission is located near $96 \mathrm{~km}$, which is consistent with three-body recombination of oxygen atoms. Gérard et al. [2008b] found that limb profiles observed at northern midlatitudes exhibit large intensity variations over short time periods. Gérard et al. [2009] described further emission limb profiles extracted from the images. They determined the vertical distribution of $\mathrm{O}_{2}\left({ }^{1} \Delta_{\mathrm{g}}\right)$ atoms using an Abel inversion of the radiance limb profiles. Assuming photochemical equilibrium for $\mathrm{O}_{2}\left({ }^{1} \Delta\right)$, they used these density profiles combined with the $\mathrm{CO}_{2}$ 
vertical distribution to determine the atomic oxygen density. Piccioni et al. [2009a] analyzed limb measurements from 42 orbits. They found that the peak altitude of the $\mathrm{O}_{2}\left({ }^{1} \Delta_{\mathrm{g}}\right)$ volume emission rate is typically located between 95 and $100 \mathrm{~km}$, with a mean value of $97.4 \pm 2.5 \mathrm{~km}$. The vertical profile is broader near the equator, with a full width at half maximum of $11 \mathrm{~km}$, a factor 2 larger than at middle latitudes. They reported that a secondary peak is frequently observed between 103 and $105 \mathrm{~km}$.

[7] VIRTIS nightside observations from Venus Express have complemented ground-based observations at much higher spatial resolution. In addition, limb observations from an orbit around Venus have given unprecedented access to the vertical distribution of the airglow layer and provided key constraints on the models. Drossart et al. [2007a] confirmed that the $\mathrm{O}_{2}$ nightglow exhibits a large spatial and temporal variability. Observations by VIRTIS in the nadir mode have been used to construct extensive maps of the Venus atmosphere in the $\mathrm{O}_{2}$ emission band [Gérard et al., 2008b; Piccioni et al., 2009a]. In nadir viewing geometry, the contamination of the $\mathrm{O}_{2}$ airglow by the thermal emission of the deeper atmosphere has to be subtracted to obtain clean $\mathrm{O}_{2}$ airglow images. The mean value, integrated over the nightside of the southern hemisphere, is typically about $0.8 \mathrm{MR}$, which is in agreement with the early groundbased observations giving a mean brightness of $1.2 \mathrm{MR}$ for the night side. Hueso et al. [2008] found that the airglow is highly inhomogeneous with the regions of highest intensity generally located at low latitudes near the midnight meridian. They showed that zonal velocity derived from the motion of airglow features is dominated by an intense prograde jet from dawn to midnight extending up to $22 \mathrm{~h}$ in local time, with lower velocities and reversed sign from dusk. The brightest small-scale $(\sim 100 \mathrm{~km})$ features appeared correlated with locations of apparent convergence which may be a signature of compression and downwelling. Piccioni et al. [2009a] described the characteristics of the horizontal distribution of the airglow and showed that regions of high $\mathrm{O}_{2}$ airglow intensity are associated with downwelling causing an increase of the infrared brightness temperature. A similar conclusion was reached by Bailey et al. [2008], who derived rotational temperatures in excess of the VIRA values in regions of enhanced $\mathrm{O}_{2}{ }^{1} \Delta$ emission rate. They associated these regions with conditions of larger downflow velocities where local temperature is increased by compressional heating. Similar and larger temperature enhancements were observed with SPICAV from measurements of UV $\mathrm{CO}_{2}$ absorption measurements during stellar occultations by Bertaux et al. [2007a]. The nonhomogeneous, time-dependent distribution of the $\mathrm{O}_{2}{ }^{1} \Delta_{\mathrm{g}}$ nightglow indicates that the local downward flow of oxygen may differ substantially from the mean value, in response to variations in the efficiency of the global day-to-night transport, the focusing effect of the nightside subsidence, changing zonal wind speeds, eddy transport efficiency, and gravity wave breaking [Bougher et al., 2006].

[8] The $\mathrm{NO}$ and $\mathrm{O}_{2}$ nightglows do not occur at the same altitude and thus provide information about different vertical levels: $95-105 \mathrm{~km}$ for $\mathrm{O}_{2}$ airglow [Piccioni et al., 2009a] and $\sim 115 \mathrm{~km}$ for NO [Gérard et al., 2008a]. In this study, we address the question of the covariation of the two airglow layers. Earlier studies have established that the statistical location of the nightglow bright spots is not coincident. This result was unexpected since the two emissions are produced by recombination of atoms created on the dayside by photodissociation and transported to the nightside by the subsolar to antisolar global circulation. In this study, we take advantage of the unique opportunity offered by two instruments of the Venus Express mission (SPICAV and VIRTIS) to observe almost simultaneously the two emissions and to investigate if their characteristics covary in time and space. The observations reported here were obtained both in nadir-viewing geometry, where horizontal variations of the emission rate can be mapped, and at the limb, where vertical variations are best investigated. We describe both types of observations and draw conclusions on the level of covariance we have observed and transport processes occurring in the Venus mesospherethermosphere transition region.

\section{Parallel Nadir Observations}

[9] The Venus Express spacecraft moves along a quasipolar eccentric orbit with a $24-\mathrm{h}$ period. The apocenter is located at $66,000 \mathrm{~km}$, while the altitude of the pericenter (at $80^{\circ} \mathrm{N}$ ) has varied between $250 \mathrm{~km}$ and $185 \mathrm{~km}$. The orbit is fixed in the inertial space and therefore precesses at the rate of $1.6^{\circ} \mathrm{d}^{-1}$. The precession of the orbital plane leads to a wide variety of configurations on the nightside as well as on the dayside. Several observation modes (science cases) may be selected including nadir observations, star pointing for stellar occultations by Venus' atmosphere, fixed point tracking and limb observations [Titov et al., 2006].

[10] The SPICAV instrument and its performances were described by Bertaux et al. [2007b]. The ultraviolet spectrometer covers a spectral range extending from $118 \mathrm{~nm}$ to $320 \mathrm{~nm}$ including the NO $\delta\left(\mathrm{C}^{2} \Pi-\mathrm{X}^{2} \Pi\right)$ and $\gamma\left(\mathrm{A}^{2} \Sigma-\right.$ $\mathrm{X}^{2} \Pi$ ) emission bands, the only spectral features with Lyman$\alpha$ observed in the Venus nightglow [Gérard et al., 2008a]. The detector is a $407 \times 288$ pixel CCD and the angular field of view of one pixel is equal to $0.7 \times 0.7$ arcmin. For reasons of telemetry limitations and because of the time needed to read all the lines of the $\mathrm{CCD}$, only 5 adjacent zones of the CCD detector are usually read out. In these nadir observations, the width of each spatial bin is 32 pixel lines, corresponding to a field of view of $3.7^{\circ}$. These lines are seen through the large $(500 \mu \mathrm{m})$ slit, providing a spectral resolution of about $12 \mathrm{~nm}$. The planetary area intercepted by the field of view depends on the location on its orbits. The spacecraft altitude ranged between 7350 and $9050 \mathrm{~km}$ during the nadir observations reported here. The SPICAV $\mathrm{CCD}$ is read out every second, but the actual integration period of each spectrum is $640 \mathrm{~ms}$. The nonuniform dark current and offset values are carefully subtracted in each individual spectrum, using similar observations performed with a null amplification. The absolute calibration obtained by observing well-known hot stars spectra is then applied to obtain nitric oxide emission rates in $\mathrm{kR}$ [Bertaux et al., 2007b].

[11] Spectral images have been regularly obtained in nadir geometry with VIRTIS mostly from segments of the orbit near apocenter. The VIRTIS [Drossart et al., 2007b; Piccioni et al., 2009b] pixel size of $0.25 \mathrm{mrad}$ gives a spatial resolution of $15 \mathrm{~km}$ on Venus from apocenter. For this 
Table 1. Time, Location, Maximum Brightness and Correlation Coefficient $\mathrm{R}$ of the Nitric Oxide and $\mathrm{O}_{2}\left({ }^{1} \Delta\right)$ Airglow Concurrent Observations by SPICAV and VIRTIS-M at Nadir

\begin{tabular}{|c|c|c|c|c|c|c|c|c|}
\hline Orbit & Start Time (UT) & Stop Time (UT) & Local Time & $\begin{array}{l}\text { Minimum } \\
\text { Latitude } \\
\text { (deg) }\end{array}$ & $\begin{array}{c}\text { Maximum } \\
\text { Latitude } \\
\text { (deg) }\end{array}$ & $\begin{array}{c}\text { Imax NO } \\
(\mathrm{kR})\end{array}$ & $\begin{array}{c}\operatorname{Imax} \mathrm{O}_{2} \\
(\mathrm{MR})\end{array}$ & $\mathrm{R}$ \\
\hline 243 & 20 Dec 2006; 0752:46 & 20 Dec 2006; 0806:29 & 0035 & 1.8 & 48.9 & 2.7 & 1.1 & 0.55 \\
\hline 341 & 28 Mar 2007; 0549:01 & $28 \operatorname{Mar} 2007 ; 0558: 43$ & 2307 & -9.3 & -5.1 & 1.0 & 0,6 & -0.84 \\
\hline 342 & 29 Mar 2007; 0547:05 & 29 Mar 2007; 0606:39 & 2314 & -10.2 & 10.9 & 3.1 & 1.1 & -0.41 \\
\hline 343 & 30 Mar 2007; 0545:17 & 30 Mar 2007; 0557:22 & 2318 & -10.9 & -0.4 & 1.0 & 2.2 & 0.74 \\
\hline 345 & 1 Apr 2007; 0542:15 & 1 Apr 2007; 0556:04 & 2330 & -11.7 & -2.3 & 2.1 & 0.9 & 0.23 \\
\hline 346 & 2 Apr 2007; 0540:55 & 2 Apr 2007; 0605:27 & 2336 & -12.0 & 14.1 & 3.7 & 3.5 & 0.32 \\
\hline 453 & 18 Jul 2007; 0710:30 & 18 Jul 2007; 0735:42 & 2306 & -16.4 & 38.1 & 1.1 & 0.6 & -0.13 \\
\hline 459 & 24 Jul 2007; 0650:06 & 24 Jul 2007; 0718:12 & 2343 & -18.8 & 37.5 & 2.2 & 0.9 & -0.08 \\
\hline 567 & 9 Nov 2007; 0055:00 & 9 Nov 2007; 0123:40 & 2312 & -10.9 & 31.6 & 3.5 & 1.1 & 0.86 \\
\hline 571 & 13 Nov 2007; 0057:30 & 13 Nov 2007; 0121:04 & 0010 & 16.4 & 19.0 & 2.5 & 1.1 & -0.59 \\
\hline 592 & 4 Dec 2007; 0213:35 & 4 Dec 2007; 0231:45 & 0156 & 13.4 & 48.3 & 6.2 & 1.4 & 0.25 \\
\hline 901 & 8 Oct $2008 ; 0811: 21$ & 8 Oct $2008 ; 0830: 11$ & 2301 & -13.1 & 20.2 & 1.7 & 0.8 & 0.44 \\
\hline 905 & 12 Oct $2008 ; 0819: 58$ & 12 Oct $2008 ; 0838: 48$ & 2328 & -12.8 & 20.2 & 2.5 & 0.7 & 0.49 \\
\hline 907 & 14 Oct $2008 ; 0824: 18$ & 14 Oct $2008 ; 0843: 08$ & 2339 & -12.7 & 20.4 & 3.9 & 0.8 & 0.26 \\
\hline
\end{tabular}

study, we use the VIRTIS-M mode which provides spectral cubes between 0.25 and $5 \mu \mathrm{m}$ at a spectral resolution $\mathrm{R} \sim$ 200. Each spectral channel is $\sim 9.5 \mathrm{~nm}$ wide in the region of the $\mathrm{O}_{2}$ Atmospheric Infrared system emission. A spatial scan, covering a $64 \mathrm{mrad} \times 64 \mathrm{mrad}$ field of view is obtained using a scanning mirror. However, even from apocenter, only a fraction of the Venus disk is observed during a mirror scan of the instrument and a spacecraft repointing is needed to collect a more extended coverage. For each VIRTIS image, the thermal contribution from the lower atmosphere is subtracted from the total signal using the VIRTIS fluxes measured in the three adjacent channels centered on $1.27 \mu \mathrm{m}$. The count rate is expressed in radiative flux units and MR using the measured instrumental calibration and the $\mathrm{O}_{2}\left({ }^{1} \Delta_{\mathrm{g}}\right)$ relative line intensity for a temperature of $200 \mathrm{~K}$. Airglow radiation emitted downward and subsequently backscattered by the underlying clouds is accounted for using the correction factor derived by Crisp et al. [1996].

[12] The SPICAV and VIRTIS databases have been searched to identify periods when the fields of view of the nadir-viewing observations of both instruments overlapped over a significant time span. Table 1 lists the orbit numbers, times, and locations of these occurrences. As an example, Figure 1 illustrates the spatial coverage in the Venus atmosphere of the SPICAV slit (in gray) and the VIRTIS images (in black) during orbit 243. As can be seen, a common region was observed by both instruments northward of $2^{\circ} \mathrm{N}$ and southward of $8^{\circ} \mathrm{S}$. The shape of the VIRTIS image coverage is defined by the combination of the decreasing spacecraft altitude during the $688 \mathrm{~s}$ of the VIRTIS exposure and a reorientation of the spacecraft close to the equator. Similarly, the footprint of the SPICAV slit moved at a nearly constant longitude, with a small deviation

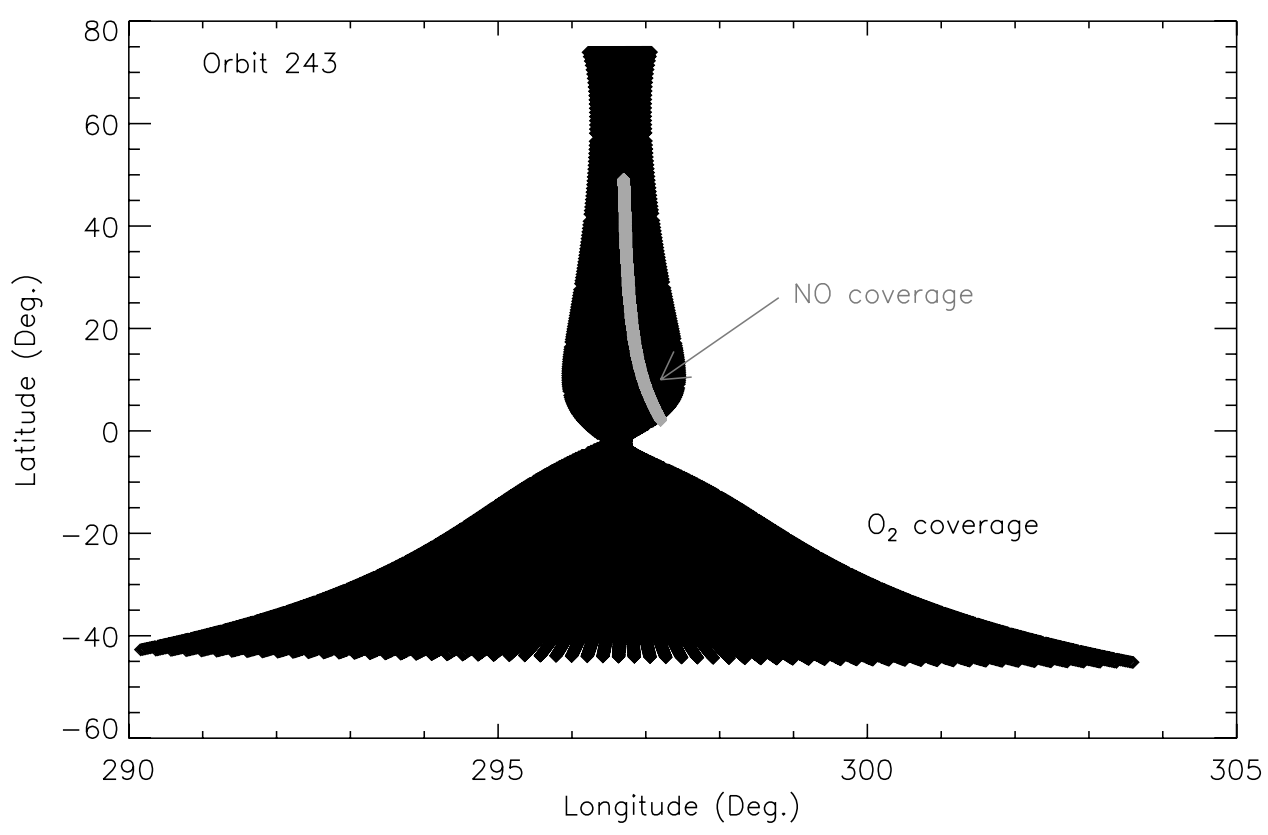

Figure 1. Spatial coverage of SPICAV (in gray) and VIRTIS-M (in black) nadir observations of the Venus nitric oxide and $\mathrm{O}_{2}\left({ }^{1} \Delta\right)$ airglow during Venus Express orbit 243. 

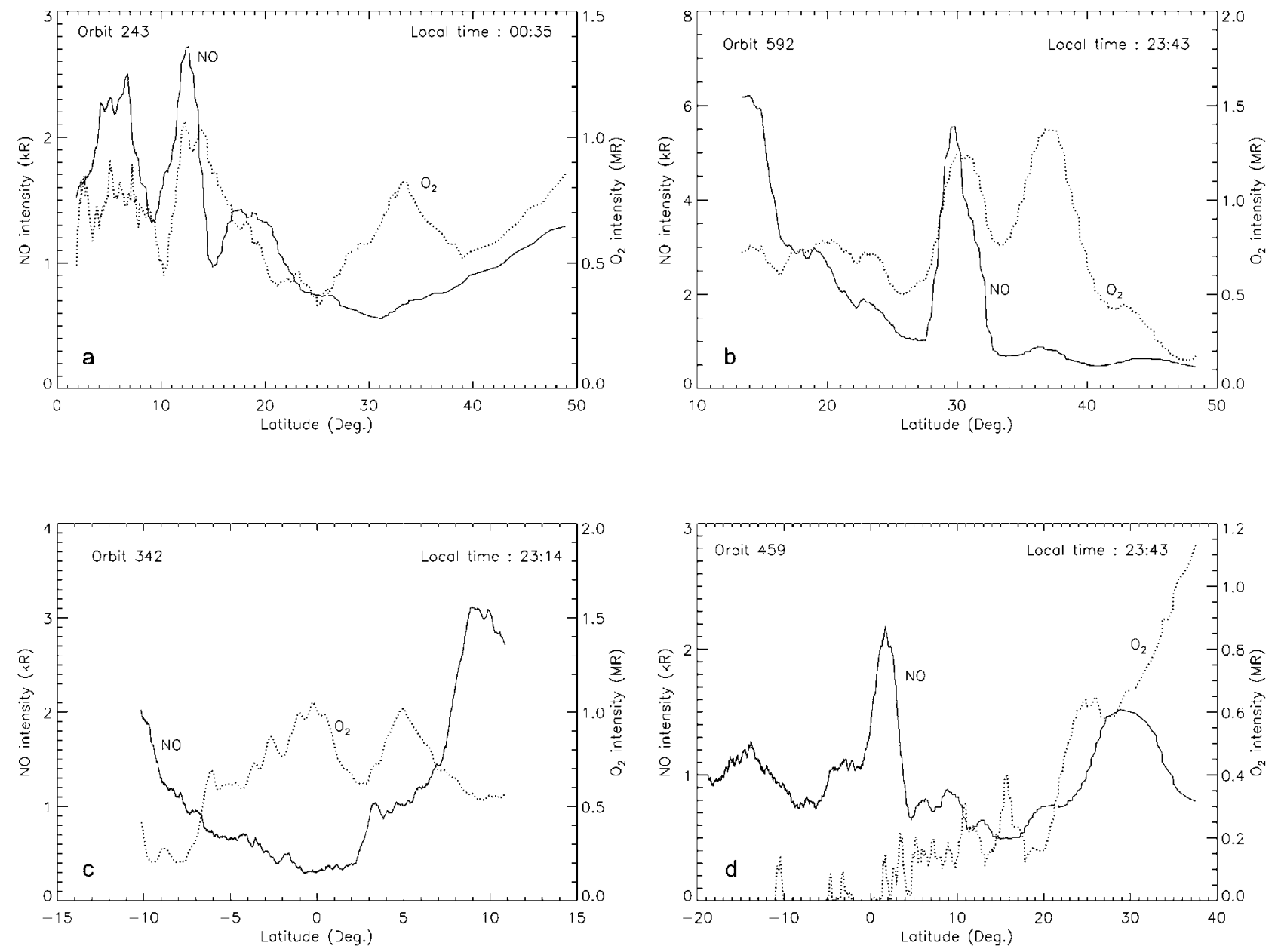

Figure 2. Examples of concurrent observations of the latitudinal distribution of nightglow intensities at nadir by VIRTIS-M and SPICAV as a function of latitude: (a) orbit 243, (b) orbit 592, (c) orbit 342, and (d) orbit 459. Note the different brightness scales used for the $\mathrm{NO}$ and the $\mathrm{O}_{2}$ airglow emission rates. The brightness at $1.27 \mu \mathrm{m}$ has been corrected for backscattered emission and both emission rates have been corrected for the view angle.

at low latitudes. Other cases of parallel observations with the two instruments present a similar pattern of spatial coverage. Once the regions of observation overlap have been identified, the brightness information is extracted from the VIRTIS nadir images along the track of the SPICAV slit. Since a VIRTIS image is constructed by combining adjacent pixel lines corresponding to successive positions of the mirror, the observations are not exactly coincident in time. The time difference is usually on the order of a few minutes. In the particular case of orbit 243 which covers a wide range of latitudes, the maximum time delay between measurements of the intensity with the two instruments at any given location varies between 4 and 16 min.

[13] Figure 2a shows the latitudinal distribution of the NO and $\mathrm{O}_{2}\left({ }^{1} \Delta_{\mathrm{g}}\right)$ nadir emission rates for this orbit measured at 0035 LT between 0752 and 0806 UT on 20 December 2006. The NO brightness is sampled once per second and a smoothing function over $10 \mathrm{~s}$ has been applied. The $\mathrm{O}_{2}$ signal has been extracted by averaging the intensity in the processed VIRTIS image over an area corresponding to the projection of one of the SPICAV spatial bins, as was shown in Figure 1. The region of parallel observations extends from close to the equator up to nearly $50^{\circ} \mathrm{N}$. In this case, two different regions are identified. The first one, southward of $\sim 25^{\circ} \mathrm{N}$ presents three successive peaks in the NO intensity with brightness ranging from 1 to $2.7 \mathrm{kR}$. The $\mathrm{O}_{2}$ airglow latitudinal variation shows structural similarities with the NO variations up to about $14^{\circ} \mathrm{N}$, with two peaks nearly coincident with the NO maxima. Further north, no clear increase of the $\mathrm{O}_{2}$ brightness corresponds to $\mathrm{NO}$ maximum at $17^{\circ} \mathrm{N}$. Northward of the location, no correlation is observed between the two signals. In particular, no feature is observed in the $\mathrm{NO}$ intensity at $33^{\circ} \mathrm{N}$ where the $\mathrm{O}_{2}$ airglow increases by over a factor two. In the lowlatitude region of the two common intensity peaks, the $\mathrm{O}_{2} /$ NO airglow intensity ratio is on the order of 500. A similar case is illustrated by Figure $2 \mathrm{~b}$ for orbit 592 where the two emissions show a different latitudinal trend equatorward of $24^{\circ} \mathrm{N}$, followed by a nearly coincident maximum near $30^{\circ}$ reaching $5.6 \mathrm{kR}$ in the NO bands and $1.2 \mathrm{MR}$ at $1.27 \mu \mathrm{m}$. The two distributions show little correlation poleward of $\sim 35^{\circ} \mathrm{N}$. In this example, the average $\mathrm{O}_{2} / \mathrm{NO}$ intensity ratio 
is again close to 500. An example of uncorrelated structures of the two airglow emissions is illustrated in Figure $2 \mathrm{c}$ which shows the latitudinal distribution measured during orbit 342 (29 March 2007) in the premidnight sector (2314 LT). In this case, no correlation is observed between $10^{\circ} \mathrm{S}$ and $11^{\circ} \mathrm{S}$. The $\mathrm{O}_{2}$ airglow exhibits a peak reaching $1 \mathrm{MR}$ on the equator and a decrease on either side of this maximum. A secondary peak is observed at $5^{\circ} \mathrm{N}$. The NO airglow presents an equatorial dip with larger intensities up to $3.2 \mathrm{kR}$ at $9^{\circ} \mathrm{N}$. In this example, the brightness ratio of the two emissions is on the order of 800 . Figure $2 d$ is another example showing no correlation between the $\mathrm{NO}$ and the $\mathrm{O}_{2}$ emissions observed during orbit 459 . It extends from $20^{\circ} \mathrm{S}$ to $38^{\circ} \mathrm{N}$, close to local midnight (2343 LT). Following correction for the thermal emission component, the $\mathrm{O}_{2}$ $\left({ }^{1} \Delta\right)$ emission rate is very weak southward of $10^{\circ} \mathrm{N}$ and hardly distinguished from the noise level. It continuously increases toward middle northern latitudes and nearly reaches the 1.2 MR level at the end of the observation sequence. Interestingly, the NO airglow shows a bright maximum of $2.2 \mathrm{kR}$ near $2^{\circ} \mathrm{N}$, a region where the $\mathrm{O}_{2}$ emission is very weak. Inversely, the $\mathrm{O}_{2}$ airglow increases poleward of $30^{\circ} \mathrm{N}$, which corresponds to a region where the NO airglow drops with increasing latitude.

[14] Concurrent sequences of the two airglow emissions have been collected during 14 Venus Express orbits. None of them shows latitudinal distribution of the two emissions which are correlated over the full observation sequence. Instead, the two features are either totally uncorrelated as in Figures $2 \mathrm{c}$ and $2 \mathrm{~d}$ or they exhibit some correlation between the locations of the intensity peaks over a limited latitudinal extent as in Figures $2 \mathrm{a}$ and $2 \mathrm{~b}$. Table 1 summarizes the dates, times and locations of the parallel airglow observations and the correlation coefficients derived from each orbital sequence. From the examples in Figure 2 and Table 1, we conclude that no large-scale correlation is generally observed in the latitudinal distribution of the vertical emission rate of the $\mathrm{NO}$ and $\mathrm{O}_{2}$ airglow. Some of the brightness enhancements are colocated over a restricted region, such as on orbit 343 , but the two latitudinal distributions may also show quite a different morphology over regions exceeding 50 degrees of latitude. We now examine concurrent limb observations of the two emissions to verify if the same conclusion holds and increase the sample size of parallel SPICAV-VIRTIS observations.

\section{Parallel Limb Observations}

[15] The observations used for this study were collected in the grazing (tangential) limb mode, where the line of sight is at some angle to the orbital plane and moves in such a way to maximize the time spent in the atmosphere [Titov et al., 2006; Bertaux et al., 2007b]. The SPICAV line of sight scans a range of altitudes, generally between $70 \mathrm{~km}$ and $400 \mathrm{~km}$ and each second a full UV spectrum is obtained. In this mode, the line of sight crosses the dark limb several times during the ascending portion of the VEX orbit. Therefore, SPICAV supplied several sets of two (one for ingress, one for egress) altitude scans of five altitude profiles at each orbit [Gérard et al., 2008a]. During these limb observations, the bin parameter varies between 2 and 32. The apparent altitude of the emission peak and its

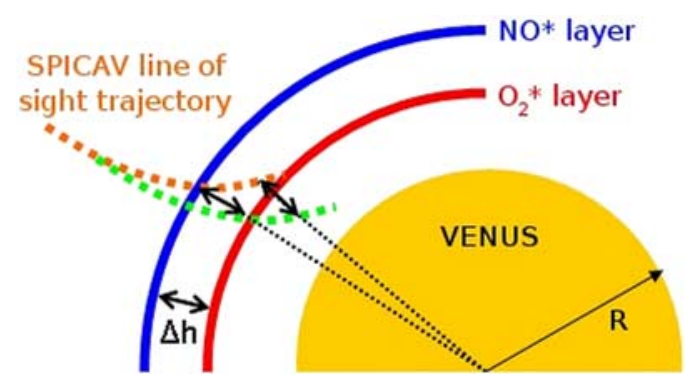

Figure 3. Sketch illustrating the methodology to generate the data point for the study of the $\mathrm{O}_{2}$ and $\mathrm{NO}$ concurrent limb observations shown in Figures 5 and 6 . The projection of the SPICAV field of view in the atmosphere is represented by the yellow dotted line. The green dotted line shows the parallel line shifted downward by a distance $\Delta \mathrm{h}$ along which the values of the $\mathrm{O}_{2}$ intensity is extracted to trace emission limb profiles such as illustrated in Figure 4.

brightness depend on the value of the field of view projected on the limb. As was discussed by Gérard et al. [2008a], the SPICAV field of view projected on the limb intercepts a vertical region whose size depends on the spacecraft limb distance, the orientation of the slit and the bin parameter. It varies from 3 to $27 \mathrm{~km}$, with a mean value of $14.9 \mathrm{~km}$. This effect is accounted for by smoothing by the field of view of an emission layer having a vertical Chapman profile integrated along the line of sight. Each Chapman profile is constrained to show the same topside scale height as the observation. SPICAV data points have been corrected for this smoothing effect by setting the peak intensity and altitude to the values they would have had if the limb profiles had been observed with a negligibly small field of view. The $0.25 \mathrm{mrad}$ pixel size of the VIRTIS-M detector projected on Venus limb corresponds to a spatial resolution of $1.9 \mathrm{~km}$ for a spacecraft distance of $7500 \mathrm{~km}$, a typical value for a VIRTIS observation at $40^{\circ} \mathrm{N}$. Analysis of the spectral cubes at the limb has indicated that the contribution of thermal radiation from the lower atmosphere is very small in the vicinity of $1.27 \mu \mathrm{m}$ for altitudes of the tangent point above $\sim 85 \mathrm{~km}$ and corrections are negligible above $95 \mathrm{~km}$ [Piccioni et al., 2009a].

[16] The possible correlation of the altitude and peak intensity of the $\mathrm{NO}$ and $\mathrm{O}_{2}$ airglows at the limb has been investigated on a statistical basis. Periods when both SPICAV and VIRTIS-M were observing the same limb region have been identified and concurrent limb profiles of the two airglows layers have been extracted. The methodology consists in first determining the limb profile of the NO airglow distribution during ingress and egress of the SPICAV line of sight in the lower thermosphere and upper mesosphere. Figure 3 illustrates the example of a profile measured for a line of sight ingress. In this sketch, the emission peaks of the two airglow layers are separated by a vertical distance taken to be equal to $15 \mathrm{~km}$ on the basis of the $\mathrm{NO}$ and $\mathrm{O}_{2}$ limb statistics. Once the $\mathrm{NO}$ emission profile is constructed, the corresponding VIRTIS limb image is scanned and pixels with a tangent point altitude located at an altitude $\Delta \mathrm{h}$ below each successive SPICAV data points are extracted from the VIRTIS cube in the $1.27 \mu \mathrm{m}$ channel. 


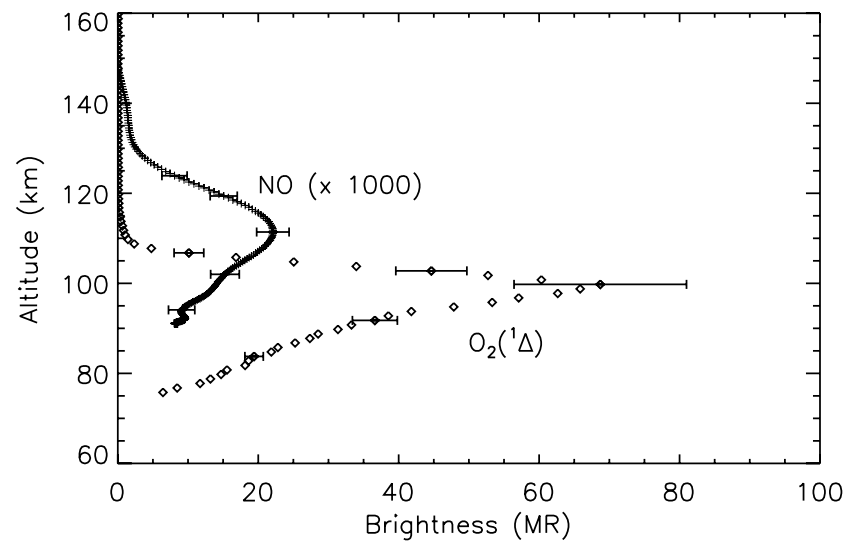

Figure 4. Example of concurrent limb profiles of the nitric oxide and $\mathrm{O}_{2}$ infrared airglow measured during Venus Express orbit 323.

In this way, an $\mathrm{O}_{2}$ limb profile is extracted from the VIRTIS-M cube so that the effects of horizontal inhomogeneity of the airglow is minimized. The time separating the acquisition of a SPICAV data point and the underlying $\mathrm{O}_{2}$ intensity is, at most, of a few minutes. In this way, quasisimultaneous profiles of the two emissions are obtained for every ingress or egress when the two instruments were simultaneously operating. Figure 4 shows a example obtained for orbit 323 (10 March 2007) between 0035 and 0047 UT at 2258 LT for an airglow layer separation of $\Delta \mathrm{h}=15 \mathrm{~km}$. The NO limb profile shows a peak of $21 \mathrm{kR}$ at $111 \mathrm{~km}$. The $\mathrm{O}_{2}$ profile reaches $69 \mathrm{MR}$ at $99.8 \mathrm{~km}$ with a fast intensity drop above the peak. Statistical error bars are indicated on the VIRTIS and SPICAV data points. A total of 249 such parallel limb profiles have been obtained between 17 January 2007 and 9 January 2008. For each profile, the altitude and brightness of the emission peaks are determined and included in the database. The results of this statistical study are summarized in Figures 5 and 6.

[17] The altitudes of the simultaneously observed NO and $\mathrm{O}_{2}$ emission profiles are shown in Figure 5. The scatterplot indicates that the intensity of the two airglow layers is not correlated, as confirmed by the very low value of the correlation coefficient $\mathrm{R}=-0.05$. The dashed line indicates equal altitudes for the $\mathrm{NO}$ and $\mathrm{O}_{2}$ emission peaks. This plot also confirms that the $\mathrm{O}_{2}$ emission peak is in most circumstances located below the NO layer. However, the distance separating the two emission peaks varies from nearly zero to as much as $28 \mathrm{~km}$, with an average of $15 \mathrm{~km}$. A detailed analysis of the four data points where the $\mathrm{O}_{2}$ peak is above the NO peak has been looked at in detail. These are specific cases when the NO airglow intensity shows a considerable latitudinal gradient as evidenced by the different peak altitudes obtained with the different SPICAV spatial bins. Since the method we use to extract the $\mathrm{O}_{2}$ limb profiles from the VIRTIS images is such that the $\mathrm{NO}$ and $\mathrm{O}_{2}$ profiles do not exactly correspond to the same observed volume, it is possible that the actual $\mathrm{O}_{2}$ emission peaks are not really located above the NO emission. The star indicates that the average altitude of the $\mathrm{NO}$ airglow peak for this data set is $113 \mathrm{~km}$ and $96.4 \mathrm{~km}$ for $\mathrm{O}_{2}\left({ }^{1} \Delta\right)$. The large scatter in the distance between the two airglows layers probably reflects

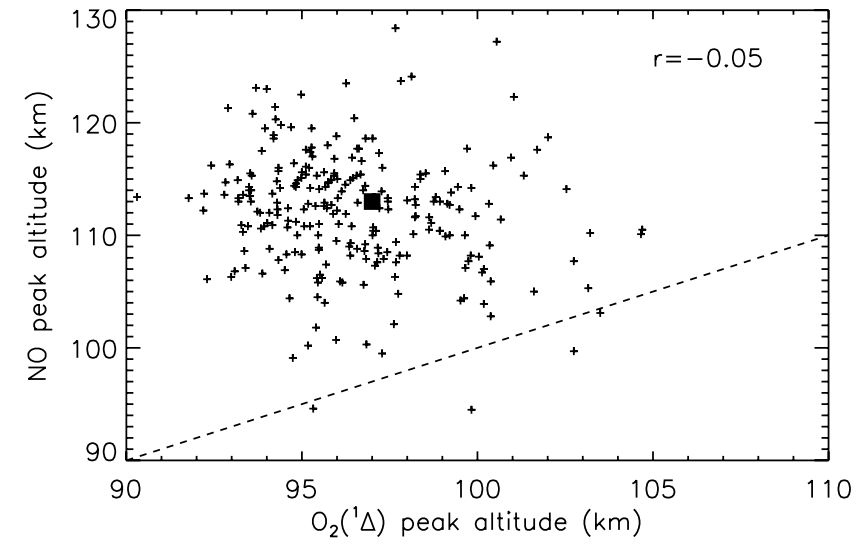

Figure 5. Altitude distribution of the emission peaks of the $\mathrm{NO}$ and $\mathrm{O}_{2}\left({ }^{1} \Delta\right)$ airglow layers measured quasisimultaneously at the limb. The observations corresponding to each point have been collected as illustrated in Figures 3 and 4 (see text). The dashed line indicates equal altitudes for the two airglow emission peaks. The correlation coefficient is -0.05 , indicating the lack of covariation of the altitude of the two emissions. The full square indicates the mean value of the peak altitude of the two emissions.

the widely changing dynamical regime prevailing in the transition region between the upper mesosphere and the lower thermosphere. A similar result is obtained when comparing the brightness of the emission peaks in parallel observations shown in Figure 6. For clarity, the $\mathrm{NO}$ and $\mathrm{O}_{2}$ brightness has been plotted on a logarithmic scale since they vary by over a wide range of values. As it was found for the peak altitude, this plot indicates that the limb brightness of the two emissions is not significantly correlated $(\mathrm{R}=0.29)$. The $\mathrm{O}_{2} / \mathrm{NO}$ intensity ratio varies by nearly 3 orders of magnitude from 55 to $\sim 40,000$. The black square indicates

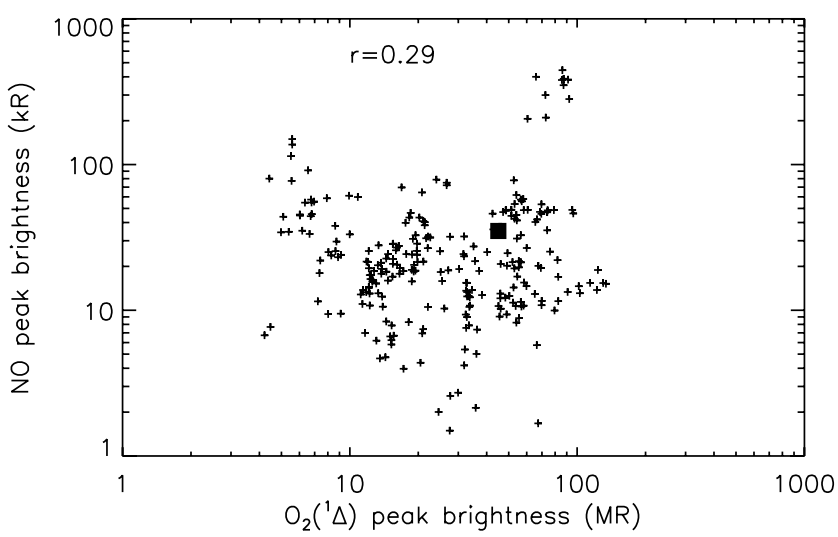

Figure 6. Brightness distribution of the emission peaks of the $\mathrm{NO}$ and $\mathrm{O}_{2}\left({ }^{1} \Delta\right)$ airglow layers measured quasisimultaneously at the limb. The observations corresponding to each point have been determined as illustrated in Figures 3 and 4 (see text). The correlation coefficient is 0.29 , indicating the lack of covariation of the brightness of the two emissions. The full square indicates the mean value of the peak intensity of the two emissions. 
that the average limb brightness of the $\mathrm{NO}$ and $\mathrm{O}_{2}$ is $45 \mathrm{kR}$ and $35 \mathrm{MR}$, respectively, in this data set, in good agreement with the statistical values of $32 \mathrm{kR}$ for NO [Gérard et al., 2008a] and $29 \mathrm{MR}$ for $\mathrm{O}_{2}\left({ }^{1} \Delta\right)$ (A. Saglam et al., Characteristics of the $\mathrm{OH}$ infrared nightglow in the Venus mesosphere and correlation with the $\mathrm{O}_{2}\left({ }^{1} \Delta\right)$ emission at $1.27 \mu \mathrm{m}$ based on VIRTIS limb observations, submitted to Advances in Space Research, 2009). The sensitivity of the results to the value of the distance $\Delta \mathrm{h}$ separating the two emission peaks has been tested by varying it by $\pm 5 \mathrm{~km}$. No significant difference was found in the results. It is thus concluded that neither the altitude of the emissions peaks nor the peak intensities at a given location in the Venus nightside atmosphere are correlated. This result is in full agreement with the independent conclusion derived from the nadir observations reported in section 2. We now examine possible explanations for these differences in the section 4 .

\section{Discussion}

[18] The observations collected with the SPICAV spectrograph and the VIRTIS-M spectral imager provide evidence that the molecular oxygen and the nitric airglow emissions are only weakly correlated. This conclusion is based on three different sets of observations. First, the statistical location of the $\mathrm{NO}$ and the $\mathrm{O}_{2}\left({ }^{1} \Delta\right)$ regions of enhanced emission are not coincident. This was demonstrated by the difference between the $\mathrm{O}_{2}$ spot centered on the equator at midnight [Gérard et al., 2008b; Piccioni et al., 2009a] and the NO maximum which is shifted by about two hours toward dawn and southward of the equator [Stewart et al., 1980; Bougher et al., 1990]. Second, nadir quasi-simultaneous observations of the two emissions reported in section 2 of this study demonstrate that the distribution of the intensity along latitudinal cuts exhibits significant differences even though the two emissions may show similarities over a limited range. Third, limb observations indicate that neither the brightness nor the altitude of the emission peak covary in the northern hemisphere. The first aspect requires additional studies and modeling. The shift of the statistical region of bright $\mathrm{NO}$ emission from the antisolar point [Stewart et al., 1980; Bougher et al., 1990; Bougher and Borucki, 1994] is an indication that the dawnward superotation observed at the cloud level persists in the upper hemisphere in such a way that the subsidence region of the global thermospheric circulation is statistically displaced by $\sim 2 \mathrm{~h}$. This result needs further SPICAV observations to confirm that the shift is still observed in a period of low solar activity conditions. If the difference between the locations of the $\mathrm{NO}$ and $\mathrm{O}_{2}$ bright regions is still observed during the Venus Express era, the picture of the vertical wind structure in the upper mesosphere-lower thermosphere transition region has to be revised accordingly.

[19] The decoupling between the characteristics of the two emissions at a given location and time raises a different question. At first glance, the results reported in this study contradict the concept of a global subsolar-to-antisolar circulation carrying the $\mathrm{O}$ and $\mathrm{N}$ atoms from their dayside source region to the nightside location where they recombine to produce the $\mathrm{NO}$ and $\mathrm{O}_{2}\left({ }^{1} \Delta\right)$ airglow emissions. In this view, the region of subsidence of the two species would

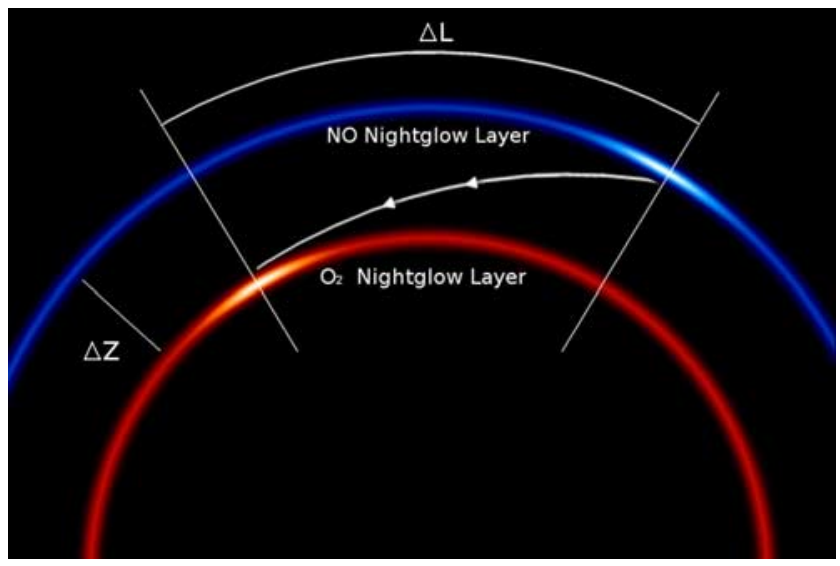

Figure 7. Sketch illustrating the role of horizontal wind in the mesosphere-thermosphere transition region as a source of spatial decorrelation between a bright spot of NO airglow and a region of enhanced $\mathrm{O}_{2}\left({ }^{1} \Delta\right)$ nightglow. The region initially enriched in oxygen atoms has traveled a horizontal distance $\Delta \mathrm{L}$ by the time the blob of O-rich gas reaches the altitude of the $\mathrm{O}_{2}$ nightglow layer located $\Delta \mathrm{z}$ km below the $\mathrm{O}_{2}$ emission peak.

be nearly coincident in the vicinity of the antisolar point. We note however that, at any given time, airglow images indicate that the location of the regions of bright emissions may considerably vary as was shown for NO [Stewart et al., 1980; Bougher et al., 1990] and $\mathrm{O}_{2}\left({ }^{1} \Delta\right)$ [Hueso et al., 2008; Piccioni et al., 2009a]. This important feature shows that the location of the subsidence of the SS-AS circulation is very variable, presumably as a consequence of an intrinsic variability of the circulation (possibly caused by the drag from gravity waves) and horizontal winds. As mentioned before, apparent wind velocities locally as large as about $100 \mathrm{~ms}^{-1}$ have been deduced by Hueso et al. [2008] from the displacement of $\mathrm{O}_{2}$ airglow features between successive VIRTIS-M images.

[20] We now take a close look at the role of horizontal winds in the decorrelation between the two airglow emissions. The two airglow layers are separated in altitude typically by $\sim 16 \mathrm{~km}$. Although this distance is limited, the time required for vertical down transport of atoms from the NO layer to the $\mathrm{O}_{2}$ emission peak is fairly long, leaving the possibility that a region richer in oxygen at $113 \mathrm{~km}$ has moved over considerable horizontal distances by the time it reaches the $97 \mathrm{~km}$ level. This situation is illustrated by the sketch in Figure 7 where an air parcel of enhanced NO emission (in white-blue) is carried over an horizontal distance $\Delta \mathrm{L}$ by the time it has reached the altitude of maximum $\mathrm{O}_{2}$ recombination $\Delta \mathrm{h}$ km below the NO layer. The effect of this horizontal transport in a situation of nonuniform downward flux above the NO airglow layer is potentially able to explain the observed decorrelation. We first need to estimate the downward velocity of an air parcel to traveling the distance $\Delta \mathrm{h}$ separating the two airglow layers. The vertical transport velocity $w$ has not been directly measured but may be estimated using models and circumstantial evidence. We examine three possible ways to derive typical vertical velocity values. First, in the one-dimensional chemical 
transport model used by Cox et al. [2008] and Gérard et al. [2008a], vertical transport below the homopause is parameterized by an eddy diffusion coefficient $\mathrm{K}$. We adopt a standard value of $\Delta Z=16 \mathrm{~km}$ for the distance separating the average altitudes of the $\mathrm{NO}$ and $\mathrm{O}_{2}$ emission peaks. On the basis of numerical simulations using the expression $\mathrm{K}=\mathrm{A} / \mathrm{n}^{1 / 2}$, we find a velocity on the order of $3 \mathrm{~cm} \mathrm{~s}^{-1}$. A second approach to estimate $\mathrm{w}$ is based on results from the three-dimensional model by Bougher et al. [1990] where eddy diffusion is relatively small. In a recent version of this model, the vertical advection velocity between 115 and $95 \mathrm{~km}$ is on the order of $15-20 \mathrm{~cm} \mathrm{~s}^{-1}$ near the antisolar point (S. W. Bougher, private communication, 2009). Finally, an estimate of the downflow velocity was also given by Bailey et al. [2008] for a nightside region with a $20 \mathrm{~K}$ temperature enhancements observed over a 2-day period. They obtained a vertical flow velocity of $\sim 20 \mathrm{~cm}$ $\mathrm{s}^{-1}$ for such a region of airglow brightening associated with enhanced vertical transport. The corresponding transit time for atoms flowing from the $\mathrm{NO}$ to the $\mathrm{O}_{2}$ airglow peak ranges between $22 \mathrm{~h}$ and 6 Earth days.

[21] The horizontal wind velocity $\mathrm{v}$ at the level of the $\mathrm{O}_{2}$ airglow layer is very variable as was recently summarized by Lellouch et al. [2008]. Winds velocities, derived from CO millimeter observations, are typically on the order of $30-50 \mathrm{~m} \mathrm{~s}^{-1}$ at $\sim 93 \mathrm{~km}$ and $90-120 \mathrm{~m} \mathrm{~s}^{-1}$ near $102 \mathrm{~km}$. Hueso et al. [2008] derived values of the effective wind velocity at $97 \mathrm{~km}$ of a few tens of m/s from the motions of bright spots of $\mathrm{O}_{2}$ airglow. Horizontal winds calculated with the 3-D model values are on the same order in the region separating the two emission layers. A crude estimate of the horizontal distance $\Delta \mathrm{L}$ crossed by moving air parcel is then given by $\Delta \mathrm{L}=\mathrm{v} / \mathrm{w} \Delta \mathrm{Z}$. Adopting a value of $\mathrm{V}=100 \mathrm{~m} \mathrm{~s}^{-1}$ as an upper limit, we find values on the order of $\sim 53,000 \mathrm{~km}$ if vertical transport is parameterized by eddy diffusion or $\sim 8000 \mathrm{~km}$ if the estimate for $\mathrm{w}$ from Bailey et al. adopted. Using $\mathrm{v}=10 \mathrm{~m} \mathrm{~s}^{-1}$ as a wind velocity probably closer to the average, we estimate a typical horizontal transport range of $\sim 800$ to 5300 to $\mathrm{km}$. Actually, the situation is further complicated by the occurrence of chemical reactions and collisional quenching which limit the chemical lifetimes of the ground state $\mathrm{O}$ atoms and the excited $\mathrm{O}_{2}\left({ }^{1} \Delta\right)$ molecules, respectively. In any case, it appears that the downward flow is much slower than the horizontal transport and atoms may travel considerable horizontal distances during their transit from 113 to $97 \mathrm{~km}$. It is therefore a direct explanation of the lack of correlation between the two emissions observed concurrently by SPICAV and VIRTIS-M. The very fact that the two emissions exhibit significant differences in their horizontal distribution strongly argues for the presence of strong horizontal winds in the thermosphere-mesosphere transition region. Other factors such as the different altitude where the $\mathrm{N}$ and the $\mathrm{O}$ atoms are formed on the dayside may play an additional role in the lack of correlation since the streamlines followed during their transport to the nightside are slightly different.

[22] On the basis of these arguments, it may now appear more difficult to understand the covariation occasionally observed in latitudinal cuts such as in Figures $2 \mathrm{a}$ and 2c. We speculate that the two emissions may covary at least under three particular conditions. First, when the distance between the two airglow layers is less than the average $16 \mathrm{~km}$. The existence of such conditions is testified by Figure 6, which shows the occurrence of cases when this distance may be reduced to only a few kilometers. Under such circumstances, the vertical downflow time and the horizontal traveled distance may also be reduced accordingly. Second, maps of the horizontal displacements of bright $\mathrm{O}_{2}$ features have indicated that regions with much smaller horizontal velocities, sometimes quasi-null values, have been observed near $97 \mathrm{~km}$. It is possible that these horizontal stagnation regions persist over a sufficiently long period of time, allowing a more vertical downflow of the oxygen atoms. Finally, local enhancements in the brightness of the $\mathrm{O}_{2}$ airglow suggest the presence of strong downflows, possibly associated with an increased vigor of local downward turbulent transport. These conditions may well explain that the two emissions can exhibit some degree of covariation, which is otherwise absent in areas of strong horizontal winds and/or weaker vertical velocity.

\section{Conclusion}

[23] The $\mathrm{O}_{2}\left({ }^{1} \Delta\right)$ and the NO $\delta$ and $\gamma$ bands night airglows of Venus have been observed concurrently for the first time by two instruments on board the Venus Express spacecraft. These observations include both nadir and limb viewing geometries. During nadir observations, the $\mathrm{O}_{2}\left(\mathrm{a}^{1} \Delta\right)$ emission intensity has been extracted from VIRTIS images observing the same locations as the footprint of the SPICAV slit in the Venus atmosphere on the same orbit. Occasional positive correlations between the latitudinal distributions of the two emissions have been observed over a limited latitudinal range. However, the overall covariability of the two airglows is low, as shown by some of the results illustrated in this study and by the globally low correlation coefficients obtained between the two sets of observational sequences. A similar conclusion is reached from the statistical comparison of the altitude and peak brightness of the two emissions simultaneously observed in the grazing limb geometry. The very low correlation coefficients of both the altitude and the intensity of the two airglow layers indicate that the transport of $\mathrm{O}$ and $\mathrm{N}$ atoms considerably deviates from a steady state vertical flow, even in the region close to the antisolar point. We suggest that the airglow decorrelation frequently observed is a consequence of the transport of the downward moving air mass by strong horizontal winds in the transition region that dynamically decouples the airglow in the two layers in a given vertical column. Our simple calculation of horizontal transport indicates that the atoms may travel considerable distances during the transit time of their vertical transport by vertical advection and eddy diffusion. Occasional correlations of the latitudinal intensity variations may be associated with situations when the distance between airglow layers is small or when the ratio of the horizontal and vertical transport velocity components is reduced. Simulations with a two- or threedimensional chemical transport model are needed to assess this scenario and quantify this effect.

[24] Acknowledgments. We gratefully thank all members of the ESA Venus Express project and of the VIRTIS ( http://servirtis.obspm.fr/Venus Express/VIRTIS_Team.html) and SPICAV scientific and technical teams. J.C.G. acknowledges funding from the Belgian Fund for Scientific Research (FNRS). A. Saglam, C. Cox, and L. Soret were supported by 
the PRODEX program managed by the European Space Agency with the help of the Belgian Federal Space Science Policy Office. This work was funded by Agenzia Spaziale Italiana and the Centre National d'Etudes Spatiales.

\section{References}

Alien, D., D. Crisp, and V. Meadows (1992), Variable oxygen airglow on Venus as a probe of atmospheric dynamics, Nature, 359, 516-519, doi:10.1038/359516a0.

Bailey, J., V. S. Meadows, S. Chamberlain, and D. Crisp (2008), The temperature of the Venus mesosphere from $\mathrm{O}_{2}\left(\mathrm{a}^{1} \Delta_{\mathrm{g}}\right)$ airglow observations, Icarus, 197, 247-259, doi:10.1016/j.icarus.2008.04.007.

Bertaux, J.-L., et al. (2007a), A warm layer in Venus' cryosphere and high altitude measurements of $\mathrm{HF}, \mathrm{HCl}, \mathrm{H}_{2} \mathrm{O}$ and $\mathrm{HDO}$, Nature, 450, 646649, doi:10.1038/nature05974.

Bertaux, J.-L., et al. (2007b), SPICAV on Venus Express: Three spectrometers to study the global structure and composition of the Venus atmosphere, Planet. Space Sci., 55, 1673-1700, doi:10.1016/j.pss.2007. 01.016 .

Bougher, S. W., and W. J. Borucki (1994), Venus $\mathrm{O}_{2}$ visible and IR nightglow: Implications for lower thermosphere dynamics and chemistry, J. Geophys. Res., 99, 3759-3776, doi:10.1029/93JE03431.

Bougher, S. W., J. C. Gérard, A. I. F. Stewart, and C. G. Fesen (1990), The Venus nitric oxide night airglow: Model calculations based on the Venus Thermospheric General Circulation Model, J. Geophys. Res., 95, 62716284, doi:10.1029/JA095iA05p06271.

Bougher, S. W., S. Rafkin, and P. Drossart (2006), Dynamics of the Venus upper atmosphere: Outstanding problems and new constraints expected from Venus Express, Planet. Space Sci., 54, 1371-1380, doi:10.1016/ j.pss.2006.04.023.

Connes, P., J. F. Noxon, W. A. Traub, and N. P. Carleton (1979), $\mathrm{O}_{2}{ }^{1} \Delta$ emission in the day and night airglow of Venus, Astrophys. J., 233, L29L32, doi:10.1086/183070.

Cox, C., A. Saglam, J.-C. Gérard, J.-L. Bertaux, F. González-Galindo, F. Leblanc, and A. Reberac (2008), The distribution of the ultraviolet nitric oxide Martian night airglow: Observations from Mars Express and comparisons with a one-dimensional model, J. Geophys. Res., 113, E08012, doi:10.1029/2007JE003037.

Crisp, D., V. S. Meadows, B. Bézard, C. de Bergh, J. P. Maillard, and F. P. Mills (1996), Ground-based near-infrared observations of the Venus nightside: $1.27 \mu \mathrm{m} \mathrm{O}_{2}\left({ }^{1} \Delta_{\mathrm{g}}\right)$ airglow from the upper atmosphere, J. Geophys. Res., 101, 4577-4594, doi:10.1029/95JE03136.

Drossart, P., et al. (1993), Search for spatial variations of the $\mathrm{H}_{2} \mathrm{O}$ abundance in the lower atmosphere of Venus from NIMS-Galileo, Planet. Space Sci., 41, 495-504, doi:10.1016/0032-0633(93)90032-W.

Drossart, P., et al. (2007a), Infrared spectral imaging observations of Venus by VIRTIS reveal a dynamical upper atmosphere, Nature, 450, 641-645, doi: 10.1038 /nature 06140

Drossart, P., et al. (2007b), Scientific goals for the observation of Venus by VIRTIS on ESA/Venus express mission, Planet. Space Sci., 55, $1653-$ 1672, doi:10.1016/j.pss.2007.01.003.

Feldman, P. D., H. W. Moos, J. T. Clarke, and A. L. Lane (1979), Identification of the UV nightglow from Venus, Nature, 279, 221-222, doi:10.1038/279221a0.

García Muñoz, A., F. P. Mills, G. Piccioni, and P. Drossart (2009), The near-infrared nitric oxide nightglow in the upper atmosphere of Venus, Proc. Natl. Acad. Sci. U. S. A., 106, 985-988, doi:10.1073/pnas. 0808091106.

Gérard, J.-C., A. I. F. Stewart, and S. W. Bougher (1981), The altitude distribution of the Venus ultraviolet airglow and implications on vertical transport, Geophys. Res. Lett., 8,633-636, doi:10.1029/ GL008i006p00633.

Gérard, J.-C., C. Cox, A. Saglam, J.-L. Bertaux, E. Villard, and C. Nehmé (2008a), Limb observations of the ultraviolet nitric oxide nightglow with
SPICAV on board Venus Express, J. Geophys. Res., 113, E00B03, doi:10.1029/2008JE003078.

Gérard, J.-C., A. Saglam, G. Piccioni, P. Drossart, C. Cox, S. Erard, R. Hueso, and A. Sánchez-Lavega (2008b), The distribution of the $\mathrm{O}_{2}$ infrared nightglow observed with VIRTIS on board Venus Express, Geophys. Res. Lett., 35, L02207, doi:10.1029/2007GL032021.

Gérard, J.-C., A. Saglam, G. Piccioni, P. Drossart, F. Montmessin, and J.-L. Bertaux (2009), Atomic oxygen distribution in the Venus mesosphere from observations of $\mathrm{O}_{2}$ infrared airglow by VIRTIS-Venus Express, Icarus, 199, 264-272, doi:10.1016/j.icarus.2008.09.016.

Hueso, R., A. Sánchez-Lavega, G. Piccioni, P. Drossart, J.-C. Gérard, I. Khatuntsev, and L. Zasova (2008), Morphology and dynamics of Venus oxygen airglow, J. Geophys. Res., 113, E00B02, doi:10.1029/ 2008JE003081.

Krasnopolsky, V. A. (1986), Oxygen emissions in the night airglow of the Earth, Venus, and Mars, Planet. Space Sci., 34, 511-518, doi:10.1016 0032-0633(86)90089-9.

Lellouch, E., T. Clancy, D. Crisp, A. Kliore, D. Titov, and S. W. Bougher (1997), Monitoring of mesospheric structure and dynamics, in Venus II: Geology, Geophysics, Atmosphere, and Solar Wind Environment, edited by S. W. Bougher et al., pp. 295-324, Univ. of Ariz. Press, Tucson.

Lellouch, E., G. Paubert, R. Morenoaand, and A. Moullet (2008), Monitoring Venus' mesospheric winds in support of Venus Express: IRAM 30-m and APEX observations, Planet. Space Sci., 56, 1355-1367, doi:10.1016/j.pss.2008.06.010.

Miller, H. C., J. E. McCord, J. Choy, and G. D. Hager (2001), Measurement of the radiative lifetime of $\mathrm{O}_{2}\left(\mathrm{a}^{1} \Delta_{\mathrm{g}}\right)$ using cavity ring down spectroscopy, J. Quant. Spectrosc. Radiat. Transfer, 69, 305-325.

Ohtsuki, S., N. Iwagami, H. Sagawa, M. Ueno, Y. Kasaba, T. Imamura, and E. Nishihara (2008), Imaging spectroscopy of the Venus $1.27-\mu \mathrm{m}, \mathrm{O}_{2}$ airglow with ground-based telescopes, Adv. Space Res., 41, 1375-1380, doi:10.1016/j.asr.2007.10.014.

Piccioni, G., L. Zasova, A. Migliorini, P. Drossart, A. Shakun, A. García Muñoz, F. P. Mills, and A. Cardesin-Moinelo (2009a), Near-IR oxygen nightglow observed by VIRTIS in the Venus upper atmosphere, J. Geophys. Res., 114, E00B38, doi:10.1029/2008JE003133.

Piccioni, G., et al. (2009b), The Visible and Infrared Thermal Imaging Spectrometer, Eur. Space Agency Spec. Publ., ESA SP-1295, in press.

Saglam, A., J.-C. Gérard, L. Soret, G. Piccioni, and P. Drossart (2009), Characteristics of the $\mathrm{OH}$ infrared nightglow in the Venus mesosphere and correlation with the $\mathrm{O}_{2}\left({ }^{1} \Delta\right)$ emission at $1.27 \mu \mathrm{m}$ based on VIRTIS limb observations, submitted to Advances in Space Research.

Stewart, A. I., and C. A. Barth (1979), Ultraviolet night airglow of Venus, Science, 205, 59-62, doi:10.1126/science.205.4401.59.

Stewart, A. I. F., J.-C. Gérard, D. W. Rusch, and S. W. Bougher (1980), Morphology of the Venus ultraviolet night airglow, J. Geophys. Res., 85, 7861 - 7870, doi:10.1029/JA085iA13p07861.

Svedhem, H., et al. (2007), Venus Express: The first European mission to Venus, Planet. Space Sci., 55, 1636-1652, doi:10.1016/j.pss.2007. 01.013 .

Titov, D. V., et al. (2006), Venus Express science planning, Planet. Space Sci., 54, 1279-1297, doi:10.1016/j.pss.2006.04.017.

J.-L. Bertaux, LATMOS, Réduit de Verrières, BP3, Route des Gâtines, F-91371 Verrières-le-Buisson, France. (Jean-Loup.Bertaux@aerov.jussieu.fr)

C. Cox, J.-C. Gérard, A. Saglam, and L. Soret, Laboratoire de Physique Atmosphérique et Planétaire, Université de Liège, B-4000 Liège, Belgium. (Cedric.Cox@ulg.ac.be; jc.gerard@ulg.ac.be; A.Saglam@ulg.ac.be; lauriane. soret@ulg.ac.be)

P. Drossart, LESIA, Observatoire de Paris, 5 Place Jules Janssen, F-92195 Meudon, France. (pierre.drossart@obspm.fr)

G. Piccioni, INAF, IASF, Via del Fosso del Cavaliere 100, I-00133 Rome, Italy. (giuseppe.piccioni@iasf-roma.inaf.it) 